\title{
Controlled Synthesis of L-Lactide- $b$ - $\varepsilon$-Caprolactone Block Copolymers Using a Rare Earth Complex as Catalyst
}

\author{
Zhiyuan Zhong, ${ }^{\dagger}$ Donghong Yu, Fenghua Meng, Zhihua Gan, \\ and Xiabin JiNG
}

Changchun Institute of Applied Chemistry, Chinese Academy of Sciences, Changchun 130022, People's Republic of China

(Received October 5, 1998)

\begin{abstract}
Well-defined block copolymers of L-lactide- $b$ - $\varepsilon$-caprolactone were synthesized by sequential polymerization using a rare earth complex, $\mathrm{Y}\left(\mathrm{CF}_{3} \mathrm{COO}\right)_{3} / \mathrm{Al}(\text { iso- } \mathrm{Bu})_{3}$, as catalyst system. The compositions of the block copolymers could be adjusted by manipulating the feeding ratio of comonomers. The characterizations by GPC, ${ }^{1} \mathrm{H} \mathrm{NMR},{ }^{13} \mathrm{C}$ NMR, and DSC displayed that the block copolymer, poly( $\varepsilon$-caprolactone- $b$-L-lactide) [P(CL- $b$-LLA)], had a narrow molecular weight distribution and well-controlled sequences without random placement. KEY WORDS Block Copolymer / Rare Earth Complex / Poly(E-caprolactone) / Poly(L-lactide) / Biodegradable /
\end{abstract}

Poly( $\varepsilon$-caprolactone) (PCL) and poly(L-lactide) (PLLA) are among the most important biodegradable/ biocompatible polymers. But either has its own defects, for example, PCL has a low melting temperature and very slow degradation rate, while PLLA degrades too fast on many occasions, often leading to adverse reactions. Block copolymers, however, afford the possibility to combine both good properties, allowing permeability of the PCL to be combined with the rapid biodegradation of PLA. ${ }^{1}$

Block copolymers of $\varepsilon$-caprolactone and lactides have been synthesized by ring-opening polymerization of $\varepsilon$-caprolactone and lactides using aluminum isopropoxide, ${ }^{2}$ and/or an $\mathrm{Al}, \mathrm{Zn} \mu$-oxoalkoxide as initiators. ${ }^{3,4}$ Endo et al. synthesized block copolymers of CL and LA using aluminum porphyrin as initiator. ${ }^{5}$ In all these cases, the block copolymers can be obtained only by sequential polymerization with $\varepsilon$-caprolactone pre-polymerizing first, due to different reactivities of the two comonomers. The formation of large amounts of homo-PLA in the resultant products is sometimes observed.

Recently, lanthanide-based catalysts for the ringopening polymerization of cyclic esters have been investigated, owing to their high catalytic activity. Stevels et al., synthesized well-defined block copolymers of LLA and $\mathrm{CL}$ using yttrium alkoxide as initiator. ${ }^{6} \mathrm{~A}$ previous paper reported that $\mathrm{Y}\left(\mathrm{CF}_{3} \mathrm{COO}\right)_{3} / \mathrm{Al}(\text { iso- } \mathrm{Bu})_{3}$ is an effective catalyst for the ring-opening polymerization of lactides and lactones. ${ }^{7}$ Based on the "living" nature of the polymerization, in this paper, well-defined block copolymers of LLA and CL were synthesized by means of sequential polymerization with LLA polymerizing first, and the compositions of the copolymers can be adjusted by the feeding ratio.

\section{EXPERIMENTAL}

\section{Materials \\ $\varepsilon$-Caprolactone (Aldrich) was dried over $\mathrm{CaH}_{2}$ for two}

weeks and distilled under reduced pressure. L-Lactide (LLA) (Aldrich, $>98 \%$ ) was recrystallized twice from ethyl acetate, washed with anhydrous ethanol, and sublimed in vacuum $\left(\mathrm{mp} 98^{\circ} \mathrm{C}\right)$. Toluene was dried over $4 \mathrm{~A}$ molecular sieve for two weeks, and refluxed $6 \mathrm{~h}$ over $\mathrm{Na}-\mathrm{K}$ alloy under argon atmosphere before using; $\mathrm{Al}$ (iso-Bu $)_{3}$ (Fluka) was used without further treatment; Yttrium trifluoroacetates, $\mathrm{Y}\left(\mathrm{CF}_{3} \mathrm{COO}\right)_{3}$, was prepared by quantitative reaction of $\mathrm{Y}_{2} \mathrm{O}_{3}$ and $\mathrm{CF}_{3} \mathrm{COOH}$, then recrystallized in distilled water, dried under reduced pressure at $70^{\circ} \mathrm{C}$ to constant weight and stored in sealed ampoules filled with argon.

\section{Catalyst Preparation}

The whole process was conducted with Schlenk skills. A prescribed $\mathrm{Ln}\left(\mathrm{CF}_{3} \mathrm{COO}\right)_{3}$, toluene and iso- $\mathrm{Bu}_{3} \mathrm{Al}$ were sequentially added into a flame-dried ampoule containing several glass beads. After vigorously shaking for $8 \mathrm{~h}$, the resulting mixture was used as catalyst for later polymerization.

\section{Block Copolymerization}

Block copolymerization was performed in a Schlenktyped ampoule. One monomer, solvent and catalyst suspension were introduced into the reactor with dried syringes in that order. After reacting for a predetermined time, the other monomer was introduced into the reacting mixture in argon. After a proper reaction time, the polymerization was terminated by injecting $\mathrm{CH}_{2} \mathrm{Cl}_{2}$ containing trace of water. The mixture was poured into large excess ethanol-water $(80: 20, \mathrm{v} / \mathrm{v})$ and stirred for $30 \mathrm{~min}$, the polymer was filtrated, washed several times with ethanol or hexane, and dried in vacuum at room temperature.

\section{Characterization Methods}

The intrinsic viscosity $[\eta]$ of poly(L-lactide) prepolymer and CL-LLA copolymers was measured in benzene at $30^{\circ} \mathrm{C}$ using an Ubbelohde viscometer.

\footnotetext{
${ }^{\dagger}$ To whom correspondence should be addressed. Present address: Department of Chemical Technology, University of Twente, P.O. Box 217, 7500 AE Enschede, The Netherlands (Fax: +31-53-4893823, Tel: +31-53-4892973, e-mail: z.zhong@ct.utwente.nl).
} 


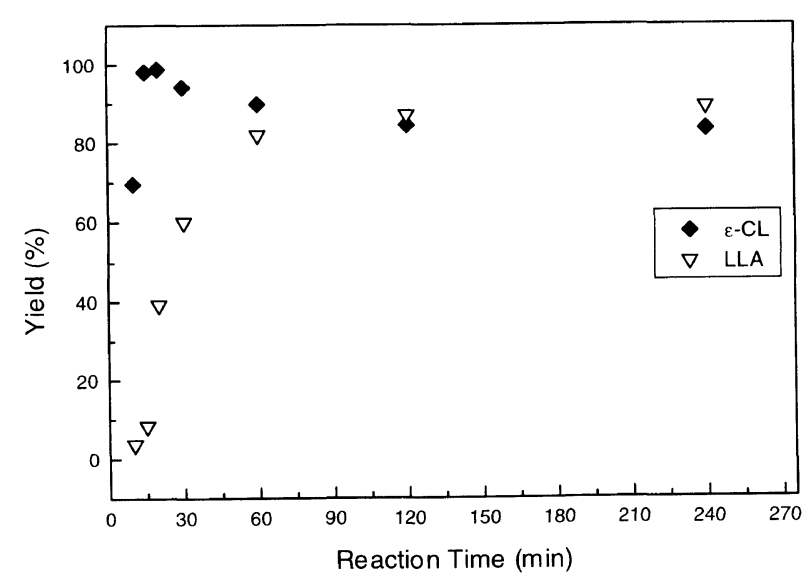

Figure 1. Yield of PCL and PLLA as a function of reaction time in a reaction mixture of $\mathrm{CL}$ and LLA 50:50 (w/w) catalyzed by $\mathrm{Y}\left(\mathrm{CF}_{3} \mathrm{COO}\right)_{3} / \mathrm{Al}(\text { iso- } \mathrm{Bu})_{3}$. ${ }^{*}$ The relative content was measured by ${ }^{1} \mathrm{H}$ NMR spectroscopy. Conditions: $[\mathrm{CL}]=2.0 \mathrm{~mol} \mathrm{~L}^{-1} ; \quad[\mathrm{CL}]$ $\left[\mathrm{Y}\left(\mathrm{CF}_{3} \mathrm{COO}\right)_{3}\right]=200\left(\mathrm{~mol} \mathrm{~mol}^{-1}\right) ;\left[\mathrm{Al}(\text { iso- } \mathrm{Bu})_{3}\right] /\left[\mathrm{Y}\left(\mathrm{CF}_{3} \mathrm{COO}\right)_{3}\right]=5$ $\left(\mathrm{mol} \mathrm{mol}{ }^{-1}\right), 110^{\circ} \mathrm{C}$, toluene.

${ }^{1} \mathrm{H}$ and ${ }^{13} \mathrm{C}$ NMR spectra were recorded in $\mathrm{CDCl}_{3}$ on a Varian Unity-400 NMR Spectrometer. The numberaverage molecular weight and molecular weight distribution of the polymers were determined by gel permeation chromatography (Waters 515) in tetrahydrofuran (THF) at $25^{\circ} \mathrm{C}$ using polystyrene as standard. Thermal properties of the polymers were measured on a PerkinElmer DSC-7 instrument.

\section{RESULTS AND DISCUSSION}

In a previous study, ${ }^{7}$ it was concluded that the ring-opening polymerization of cyclic esters using $\mathrm{Y}\left(\mathrm{CF}_{3} \mathrm{COO}\right)_{3} /$ iso- $\mathrm{Bu}_{3} \mathrm{Al}$ as catalyst has a living nature. Taking advantage of this, CL- $b$-LLA block copolymers were synthesized successfully by sequential polymerization, as shown in Table I. The feeding order, however, had great influence on CL-LLA block copolymerization. Active species obtained by LLA being firstly polymerized initiated the polymerization of $\mathrm{CL}$, resulting in block copolymer of well-controlled chain lengths. In contrast, active species deriving from CL failed to initiate the polymerization of LLA. It should be noted that this differs from those of many papers published before. ${ }^{2,8}$ This can be explained by the completely different reactivities of the comonomers. It has been proven that lactides have a much larger reactivity than $\varepsilon$-caprolactone in copolymerization when initiated by aluminum isopropoxide or stannous octoate. ${ }^{9}$ While ring-opening polymerization of lactides and $\varepsilon$-caprolactone using $\mathrm{Y}\left(\mathrm{CF}_{3} \mathrm{COO}\right)_{3} / \mathrm{Al}(\text { iso- } \mathrm{Bu})_{3}$ as catalyst is characterized by a larger reactivity of $\varepsilon$-caprolactone. The difference in reactivity is clearly illustrated in Figure 1. It can be seen from Figure 1 that $\varepsilon$-caprolactone is preferentially polymerized in the first polymerization stage, and the homo-polymerization of L-lactide becomes much faster after most $\varepsilon$-caprolactone has been consumed, with no random copolymers resulting.

Table I shows the block copolymerization results of poly( $\varepsilon$-caprolactone- $b$-L-lactide) (P(CL- $b$-LLA $)$ performed with various feed mole ratios, from which it can be found that although yields are not high, the intrinsic
Table I. Block copolymerization results for $\mathrm{P}(\varepsilon-\mathrm{CL}-b$-LLA) performed at various feed mole ratios ${ }^{\mathrm{a}}$

\begin{tabular}{clllllll}
\hline No. & $f_{\mathrm{CL}}{ }^{\mathrm{b}}$ & $F_{\mathrm{CL}}{ }^{\mathrm{c}}$ & Yield $/ \%$ & {$[\eta]^{\mathrm{d}}$} & $M_{n} / 10^{4}$ & $M_{w} / 10^{4}$ & $M W D$ \\
\hline $\mathrm{c}-11-0$ & 0 & - & 72.9 & 0.249 & 1.08 & 1.37 & 1.27 \\
$\mathrm{c}-11-1$ & 0.10 & 0.05 & 68.9 & 0.255 & 1.27 & 1.59 & 1.26 \\
$\mathrm{c}-11-2$ & 0.25 & 0.15 & 57.2 & 0.268 & 1.44 & 1.86 & 1.29 \\
$\mathrm{c}-11-3$ & 0.50 & 0.52 & 72.5 & 0.434 & 2.44 & 3.20 & 1.31 \\
$\mathrm{c}-11-4$ & 0.75 & 0.77 & 74.2 & 0.808 & 3.34 & 4.48 & 1.34 \\
\hline
\end{tabular}

${ }^{\mathrm{a}}[\mathrm{LLA}] /\left[\mathrm{Y}\left(\mathrm{CF}_{3} \mathrm{COO}\right)_{3}\right]=200\left(\mathrm{~mol} \mathrm{~mol}^{-1}\right) ;\left[\mathrm{Al}(\mathrm{iso}-\mathrm{Bu})_{3}\right] /\left[\mathrm{Y}\left(\mathrm{CF}_{3}\right.\right.$ $\left.\mathrm{COO})_{3}\right]=5\left(\mathrm{~mol} \mathrm{~mol}^{-1}\right) ;[\mathrm{LLA}]=2.0 \mathrm{~mol} \mathrm{~L}^{-1} ; T=110^{\circ} \mathrm{C} ;$ toluene, $4 \mathrm{~h} .{ }^{\mathrm{b}}$ Feed molar fraction of CL. ${ }^{\mathrm{c}}$ Molar fraction of CL units in the block copolymers measured by ${ }^{1} \mathrm{H}$ NMR spectroscopy. ${ }^{\mathrm{d}}$ Intrinsic viscosity of the copolymers measured in benzene at $30^{\circ} \mathrm{C}$ using an Ubbelohde viscometer.

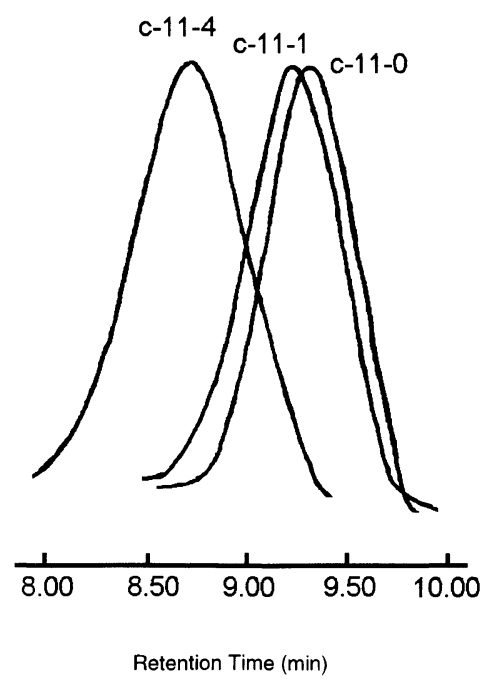

Figure 2. GPC curves of PLLA prepolymer (c-11-0) and P(LLA- $b$ CL) diblock copolymers.

viscosity of the block copolymers increases as the second monomer $(\mathrm{CL})$ was added and the more the $\mathrm{CL}$ was introduced, the higher the intrinsic viscosity of the products.

GPC results also proved the same change tendency of molecular weight, as shown in Figure 2. GPC traces of the copolymers obtained after the completion of the second polymerization stage shift appreciably to a higher molecular weight direction, and the more the second monomer (CL) was added, the higher the molecular weights of the resulting copolymers. While the molecular weight distribution stay relatively narrow and the curves of the copolymers appear completely symmetric, all of these results corroborate the absence of homopolymers in the products.

Kricheldorf et al. ${ }^{10,11}$ studied the copolymerization of lactones and lactides, and concluded that in principle, ${ }^{1} \mathrm{H}$ NMR spectroscopy is most suitable for comonomer ratio determination, while ${ }^{13} \mathrm{C}$ NMR spectroscopy is better suited for sequence analysis than ${ }^{1} \mathrm{H} N M R$, since ${ }^{1} \mathrm{H}$ NMR signals of copolyesters are not sensitive to sequence effects. Figure 3 shows the typical ${ }^{1} \mathrm{H}$ NMR spectra of the PLLA prepolymer and CL-LLA block copolymers. The compositions of copolymers could be directly calculated by the integration ratio of signal at $4.06 \mathrm{ppm}$ (PCL) to $5.16 \mathrm{ppm}$ (PLLA) in P (CL- $b$-LLA). 


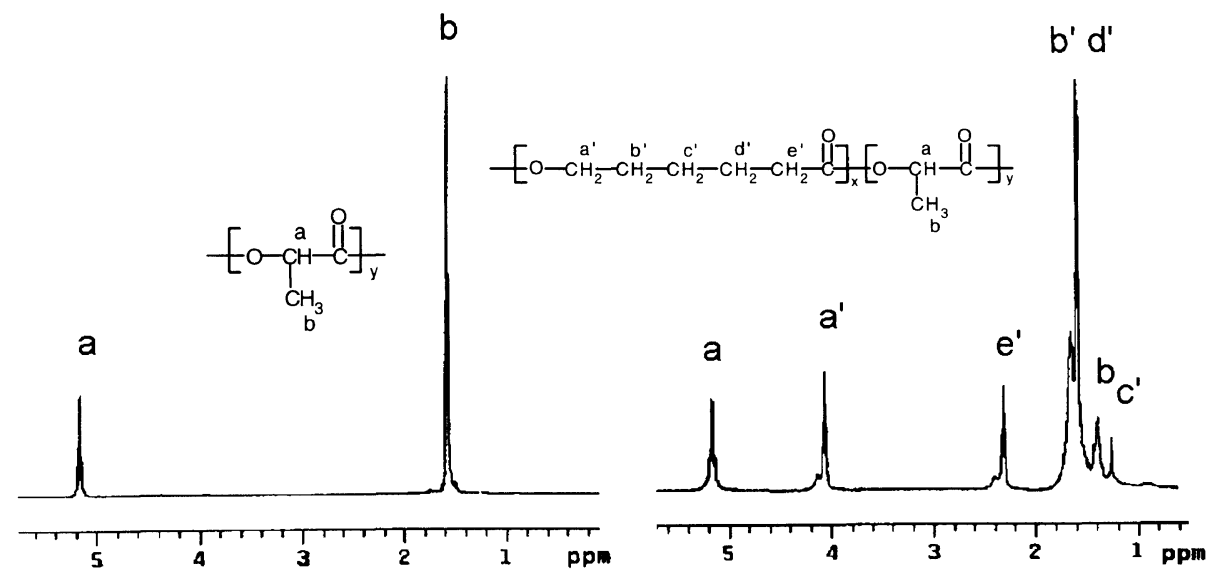

(a)

(b)

Figure 3. Typical ${ }^{1} \mathrm{H}$ NMR spectra of the PLLA prepolymer (c-11-0) and P(LLA- $b$-CL) block copolymer (c-11-3). (a) PLLA prepolymer (c-11-0); (b) LLA-CL block copolymer (c-11-3).

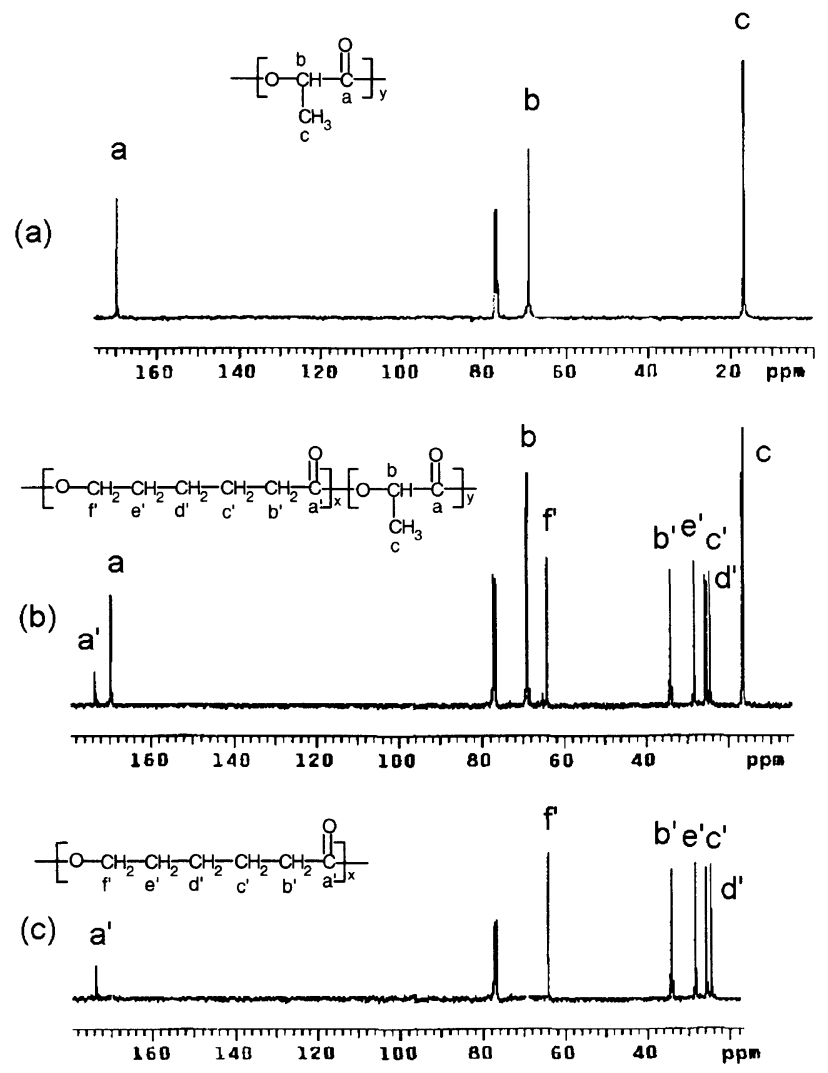

Figure 4. ${ }^{13} \mathrm{C}$ NMR spectra of LLA prepolymer, PCL homopolymer and $\mathrm{P}(\mathrm{CL}-b$-LLA) (a) PLLA prepolymer (c-11-0), (b) P(CL- $b$-LLA) (C-11-3), and (c) PCL homopolymer.

The results (Table I) indicate that the compositions of CL-LLA block copolymers catalyzed by $\mathrm{Y}\left(\mathrm{CF}_{3} \mathrm{COO}\right)_{3} /$ iso- $\mathrm{Bu}_{3} \mathrm{Al}$ can be perfectly controlled by altering the initial molar ratio of CL to LLA.

The ${ }^{13} \mathrm{C}$ NMR spectra of LLA prepolymer, PCL homopolymer, and block copolymers of CL with LLA are shown in Figure 4. It should be noted that no signals due to the random sequences of CL with LLA appeared between $173.4 \mathrm{ppm}$ (carbonyl signal of PCL block) and $169.5 \mathrm{ppm}$ (carbonyl group in PLA block) in the $\mathrm{P}(\mathrm{CL}-$

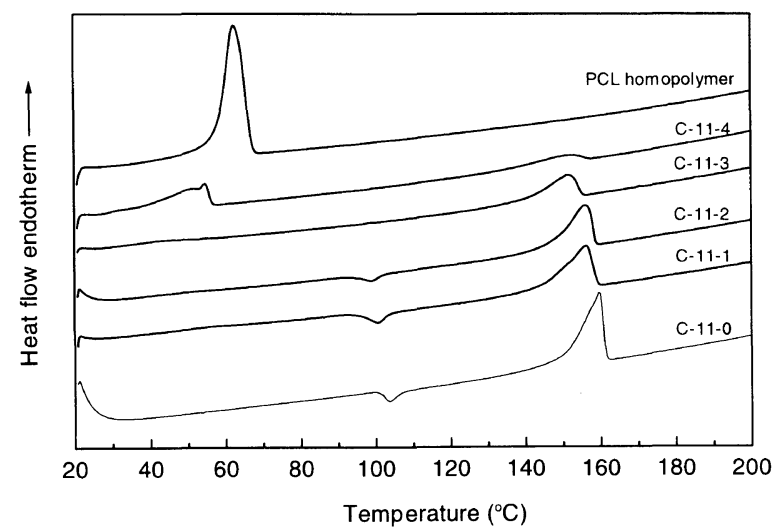

Figure 5. DSC traces of P(LLA- $b$-CL) samples of different compositions at a heating rate of $20^{\circ} \mathrm{C} \mathrm{min}^{-1}$.

$b$-LLA) spectrum, which fully demonstrating that the block copolymerization of CL and LLA was free from any transesterification and the block copolymer has a pure diblock structure. ${ }^{12,13}$

Block copolymers of different compositions were analyzed by differential scanning calorimeter (DSC). Figure 5 shows that PLLA prepolymer and PCL homopolymer are crystalline polymers, with a well-defined maximum at $156^{\circ} \mathrm{C}$ and $57^{\circ} \mathrm{C}$, respectively. The copolymerization of small amounts of $\mathrm{CL}$ comonomer to PLLA prepolymer results in decrease of melting temperature $\left(T_{\mathrm{m}}\right)$ and the enthalpy of fusion $(\Delta H)$, with no PCL melting peak was detected until the molar fraction of CL units was $77 \%$. The presence of two peaks in the block copolymer containing $77-\mathrm{mol} \% \mathrm{CL}$ indicates there are two different types of crystals in the samples, corresponding to PCL crystals and PLLA crystals. The crystallization of PCL chain in the block copolymers is limited to copolymer compositions rich in $\mathrm{CL}$, while PLLA block can crystallize within a far larger composition extent, and the higher the content of PCL, the lower the melting temperature of the PLLA block.

It can be concluded that the block copolymers of $\varepsilon$-caprolactone and L-lactide synthesized using $\mathrm{Y}\left(\mathrm{CF}_{3^{-}}-\right.$ 
$\mathrm{COO})_{3} / \mathrm{Al}(\text { iso- } \mathrm{Bu})_{3}$ as catalyst have pure block structures without random sequence, and their compositions can be controlled by varying feeding ratios of the comonomers.

\section{REFERENCES}

1. C. X. Song, H. F. Sun, and X. D. Feng, Polym. J., 19, 485 (1987).

2. C. Jacobs, Ph. Dubois, R. Jéróme, and Ph. Teyssié, Macromolecules, 24, 3027 (1991).

3. X. D. Feng, C. X. Song, and W. Y. Chen, J. Polym. Sci., Polym. Lett. Ed., 21, 593 (1983).

4. C. X. Song and X. D. Feng, Macromolecules, 17, 2764 (1984).
5. M. Endo, T. Aida, and S. Inoue, Macromolecules, 20, 2982 (1987).

6. W. M. Stevels, M. J. K. Ankoné, P. J. Dijkstra, and J. Feijen, Macromol. Chem. Phys. 196, 1153 (1995).

7. J. Zhang, Z. Gan, Z. Zhong, and X. Jing, Polym. Int., 45, 60 (1998).

8. Y. Shen, Z. Shen, Y. Zhang, and K. Yao, Macromolecules, 29, 8289 (1996).

9. D. W. Grijpma and A. J. Pennings, Polym. Bull., 25, 335 (1991).

10. H. R. Kricheldorf, J. M. Jonté, and M. Berl, Macromol. Chem. Suppl., 25, 38 (1985).

11. H. R. Krichedorf, M. Berl, and N. Scharnagl, Macromolecules, 21, 286 (1988)

12. Y. Q. Shen, K. J. Zhu, and Z. Q. Shen, J. Polym. Sci., Part A, Polym. Chem. Ed., 34, 1799 (1996). 